\title{
Endourology/Urolithiasis
}

\section{Predictive Factors for Bleeding During Percutaneous Nephrolithotomy}

\author{
Jeong Kuk Lee, Bum Soo Kim, Yoon Kyu Park \\ Department of Urology, Kyungpook National University School of Medicine, Daegu, Korea
}

Purpose: Although percutaneous nephrolithotomy (PCNL) has been accepted as a standard method for the management of large renal stones, the incidence of renal hemorrhage is relatively high. This study investigated the variables that affect bleeding during PCNL.

Materials and Methods: The medical records of 370 patients who underwent PCNL by a single surgeon from January 2005 to December 2010 were reviewed retrospectively. All patients were divided into two groups according to median blood loss (lesser bleeding group and higher bleeding group). Various clinical and perioperative factors including age, sex, stone size and position, degree of hydronephrosis, operative time, underlying disease, history of anticoagulant medication, presence of previous nephrostomy catheter, stone composition, and thickness of the renal cortex were assessed. For statistical assessment, univariate and multivariate logistic regression analyses were used.

Results: The mean patient age was 48.8 years (range, 22 to 75 years). Forty-three patients $(11.6 \%)$ received a transfusion and 9 patients $(2.4 \%)$ underwent angioembolization after surgery. The mean blood loss was $511.8 \pm 341.3 \mathrm{~mL}$. Body mass index (BMI), stone size, stone position, operation time, and degree of preoperative hydronephrosis were predictive factors for severe bleeding during PCNL.

Conclusions: On the basis of the results achieved by a single surgeon, staghorn stones, high BMI, large stones, prolonged operation time, and absence of hydronephrosis were significantly associated with the risk of severe bleeding during PCNL.

\section{Keywords: Hemorrhage; Kidney calculi; Percutaneous nephrolithotomy}

This is an Open Access article distributed under the terms of the Creative Commons Attribution Non-Commercial License (http://creativecommons.org/licenses/by-nc/3.0) which permits unrestricted non-commercial use, distribution, and reproduction in any medium, provided the original work is properly cited.

\author{
Article History: \\ received 19 August, 2012 \\ accepted 13 May, 2013
}

\author{
Corresponding Author: \\ Yoon Kyu Park \\ Department of Urology, \\ Kyungpook National University \\ Medical Center, Kyungpook \\ National University School of \\ Medicine, 130 Dongdeok-ro, \\ Jung-gu, Daegu 700-721, Korea \\ TEL: +82-53-420-5852 \\ FAX: +82-53-421-9618 \\ E-mail: uropark@knu.ac.kr
}

\section{INTRODUCTION}

Since the first report of the removal of renal stones via nephrostomy by Rupel and Brown [1] in 1941, there have been significant improvements in techniques, instruments, and experience. Fernastrom and Johansson first reported percutaneous nephrolithotomy (PCNL) in 1976 [2], and Alken et al. [3] introduced the renal endoscope and ultrasonic lithotripsy to further the development of the technique. Although extracorporeal shock wave lithotripsy (ESWL) and flexible ureteroscopic stone removal are widely used treatment modalities for renal stones, PCNL is still needed for selected cases according to the size, position, shape, and composition of the stones [3].
PCNL was reported to cause fewer complications and to reduce the length of hospital stay compared with anatrophic nephrolithotomy. PCNL is recommended for cases with stones larger than $2 \mathrm{~cm}$, cases with struvite or cystine stones, cases in which stone removal failed with ESWL, or cases accompanied by anatomical malformation [4,5]. However, PCNL does carry a risk of significant morbidity, with contemporary series describing a complication rate of $20.5 \%$ [6] and transfusion rates varying enormously between $<1 \%$ and 55\% [7-11]. Moreover, perioperative renal bleeding is one of the most common and worrisome complications of PCNL [8]. Although most bleeding associated with PCNL can be managed conservatively, approximately $0.8 \%$ of patients require intervention to control severe 
bleeding [12]. Thus, a surgeon should notice early the complications during and after the operation and prepare the appropriate management. Traditionally, diabetes, staghorn stone, method of dilatation, and stone size were reported as predictive factors of bleeding $[8,13]$. However, the risk factors in Korea are not yet well known. We aimed to identify the predictive factors for bleeding by retrospectively analyzing patients who underwent PCNL at Kyungpook National Univerdity Medical Center.

\section{MATERIALS AND METHODS}

This study was a retrospective analysis of 370 patients who underwent PCNL at Kyungpook National Univerdity Medical Center between January 2005 and December 2010. All surgeries were performed by a single surgeon via a single nephrostomy tract. All patients underwent preoperative computed tomography (CT), and the mean size of the stone was measured from the area of the whole stone shown in the CT. The amount of blood loss was measured by use of the formula for actual blood loss [14]. The patients consisted of 232 male patients $(62.7 \%)$ and 138 female patients $(37.3 \%$ ) with a mean age of 48.8 years (range, 22 to 75 years) (Table 1 ).

All patients were administered preventive intravenous antibiotics 24 to 48 hours before surgery. Except for 24 patients with preexisting nephrostomy, in 346 patients, nephrostomy tract puncture under local anesthesia was conducted to indwell a guide wire by a preoperative cooperative procedure with the department of radiology, and nephrostomy dilatation and lithotripsy were conducted with the patient under general anesthesia.

A balloon catheter ( $5 \mathrm{Fr}$ ) was laid in the ureteropelvic junction to prevent the stone fragments from migrating to the ureter during the operation. Then, the nephrostomy

TABLE 1. Patients' characteristics

\begin{tabular}{lc}
\hline \multicolumn{1}{c}{ Characteristic } & Value \\
\hline No. of patients & 370 \\
Age (yr), mean (range) & $48.8(22-75)$ \\
Sex (male/female) & $232 / 138$ \\
Stone position & \\
Staghorn & $154(41.5)$ \\
Renal pelvis & $98(26.5)$ \\
Calyceal & $71(19.2)$ \\
Upper ureter & $47(12.8)$ \\
Stone size (mm $\left.{ }^{2}\right)$ & $337.54 \pm 227.19$ \\
Body mass index $\left(\mathrm{kg} / \mathrm{m}^{2}\right)$ & $24.2 \pm 2.7$ \\
Bilateral stone & $47(12.7)$ \\
Laterality & \\
Right & $177(47.8)$ \\
Left & $193(52.2)$ \\
Blood loss (mL) & $511.8 \pm 341.3$ \\
Median & 498.6 \\
\hline
\end{tabular}

Values are presented as number $(\%)$ or mean \pm standard deviation unless otherwise indicated. was extended to $30 \mathrm{Fr}$ via the indwelled guide wire by use of balloon dilatation. The stones were removed by forceps after lithotripsy with an ultrasonic lithotriptor and ballistic lithotriptor. Finally, a 24-Fr nephrostomy catheter was indwelled after the completion of the operation.

The composition of all stones was analyzed postoperatively and classified in accordance with the composition of the highest component. The types (location) of renal stones included staghorn (154 cases, $41.5 \%$ ), renal pelvis (98 cases, $26.5 \%$ ), calyx (71 cases, $19.2 \%$ ), and upper ureter (47 cases, $12.8 \%$ ) stones. The mean stone burden was $337.54 \pm 227.1 \mathrm{~mm}^{2}$, and mean blood loss was $511.8 \pm 341.3$ mL (Table 1).

The median blood loss was $498.6 \mathrm{~mL}$. The patients were divided according to blood loss into group A, whose blood loss was less than the median blood loss $(n=185)$, and group $\mathrm{B}$, whose blood loss was higher than the median blood loss $(n=185)$. The two groups were compared and analyzed according to their age, sex, body mass index (BMI), stone size, type (location) and composition of stone, operation time, severity of preoperative hydronephrosis, underlying disease, history of abdominal surgery, and thickness of the renal cortex to identify associations with blood loss. Statistical analyses were implemented by using the IBM SPSS ver. 18.0 (IBM Co., Armonk, NY, USA). Student t test was used to compare the stone size and the BMI. Other factors were assessed by chi-square test. Then, logistic regression analysis was applied for multivariate analysis. A p-value of $<0.05$ was considered statistically significant.

\section{RESULTS}

The mean operation time was $100.4 \pm 14.5$ minutes, and the mean length of hospital stay was $10.3 \pm 3.5$ days. Among 370 patients, 43 patients (11.6\%) were transfused and $9(2.4 \%)$ underwent angioembolization after the operation, and none of them required reoperation. The mean age of group A was 49.3 years (range, 22 to 75 years) and that of group B was 48.3 years (range, 28 to 72 years), with no significant difference between the groups. Group A included 120 male patients $(64.9 \%)$ and 62 female patients $(35.1 \%)$, and group $\mathrm{B}$ included 112 male patients $(60.5 \%)$ and 72 female patients $(39.5 \%)$. Thus, there were more males in group A, but the difference was not statistically significant. The mean blood loss was $270.5 \pm 139.7 \mathrm{~mL}$ for group A and $753.1 \pm 270.7$ $\mathrm{mL}$ for group B (Table 2). Mean BMI was $23.3 \pm 2.4 \mathrm{~kg} / \mathrm{m}^{2}$ (group A) and $25.1 \pm 2.9 \mathrm{~kg} / \mathrm{m}^{2}$ (group B). Group B had a significantly higher BMI in both the univariate and the multivariate comparisons $(\mathrm{p}<0.001$ and $\mathrm{p}=0.032)$.

The mean stone size was $271.7 \pm 217.7 \mathrm{~mm}^{2}$ in group A and $403.3 \pm 220.5 \mathrm{~mm}^{2}$ in group $\mathrm{B}$, respectively, indicating a significantly larger stone size in group $B(p<0.001$ and $\mathrm{p}=0.048$ ). In terms of stone position, the rate of staghorn stones was significantly higher but the rates of calyx and upper ureter stones were significantly lower in group $B(p$ $<0.001$ and $p=0.001$ ). When the numbers of stones were classified into single and multiple, group A included 83 cas- 
TABLE 2. Comparison of clinical and perioperative factors between higher and lesser bleeding groups

\begin{tabular}{|c|c|c|c|}
\hline Variable & Group A $(\mathrm{n}=185)$ & Group B $(\mathrm{n}=185)$ & $\mathrm{p}$-value \\
\hline Blood loss (mL) & $270.5 \pm 139.7$ & $753.1 \pm 270.7$ & $<0.001$ \\
\hline Age (y), mean (range) & $49.3\left(22^{-75)}\right.$ & $48.3(28-72)$ & 0.362 \\
\hline Sex (male/female) & $120 / 65$ & $112 / 72$ & 0.754 \\
\hline Body mass index $\left(\mathrm{kg} / \mathrm{m}^{2}\right)$ & $23.3 \pm 2.4$ & $25.1 \pm 2.9$ & $<0.001$ \\
\hline \multicolumn{4}{|l|}{ Underlying disease } \\
\hline Hypertension & $32(17.3)$ & $31(16.8)$ & 0.871 \\
\hline Diabetes mellitus & $15(8.1)$ & $22(11.9)$ & 0.121 \\
\hline Cardiovascular accident & $2(1.1)$ & $4(2.2)$ & 0.524 \\
\hline Chronic renal failure & $3(1.6)$ & $7(3.8)$ & 0.112 \\
\hline Chronic liver disease & $2(1.1)$ & $3(1.6)$ & 0.677 \\
\hline Stone position & & & $<0.001$ \\
\hline Staghorn & $48(25.9)$ & $106(57.3)$ & \\
\hline Renal pelvis & $52(28.1)$ & $46(24.9)$ & \\
\hline Calyx & $52(28.1)$ & $19(10.3)$ & \\
\hline Upper ureter & $33(17.8)$ & $14(7.6)$ & \\
\hline Stone size $\left(\mathrm{mm}^{2}\right)$ & $271.7 \pm 227.7$ & $403.3 \pm 220.5$ & $<0.001$ \\
\hline No. of stones & & & 0.551 \\
\hline Single & $83(44.9)$ & $65(36.8)$ & \\
\hline Multiple & $102(55.1)$ & $120(63.2)$ & \\
\hline Opacity & & & 0.613 \\
\hline Radioopaque & $134(72.4)$ & $130(70.3)$ & \\
\hline Radiolucent & $51(27.6)$ & $55(29.7)$ & \\
\hline Preoperative hydronephrosis & & & 0.004 \\
\hline None & $49(26.5)$ & $71(38.4)$ & \\
\hline Mild & $55(29.7)$ & $57(30.8)$ & \\
\hline Moderate & $60(32.4)$ & $42(22.7)$ & \\
\hline Severe & $21(11.4)$ & $15(8.1)$ & \\
\hline Previous abdominal operation & $12(6.5)$ & $13(7.0)$ & 0.783 \\
\hline Operative time $(\min )$ & $87.3 \pm 32.7$ & $113.6 \pm 48.3$ & $<0.001$ \\
\hline Stone composition & & & 0.564 \\
\hline Calcium oxalate & $83(44.9)$ & $88(47.6)$ & \\
\hline Calcium phosphate & $35(18.9)$ & $26(14.1)$ & \\
\hline Struvite & $24(13.0)$ & $32(17.3)$ & \\
\hline Uric acid & $40(21.6)$ & $36(19.5)$ & \\
\hline Cystine & $3(1.6)$ & $3(1.6)$ & \\
\hline Previous PCN & $14(7.6)$ & $10(5.4)$ & 0.711 \\
\hline Anticoagulant medication & $16(8.6)$ & $18(9.7)$ & 0.835 \\
\hline Thickness of renal cortex (mm) & $20.31 \pm 6.99$ & $27.41 \pm 10.27$ & 0.233 \\
\hline
\end{tabular}

Values are presented as mean \pm standard deviation or number $(\%)$ unless otherwise indicated.

PCN, percutaneous nephrostomy.

es (44.9\%) of single stones and 102 cases $(55.1 \%)$ of multiple stones, whereas group B had 65 cases $(36.8 \%)$ of single stones and 120 cases $(63.2 \%)$ of multiple stones. Thus, group A had a higher rate of single stones but without a statistically significant difference $(\mathrm{p}=0.551)$. Furthermore, no significant difference was found between the two groups in radiopacity ( $\mathrm{p}=0.613$ ). In terms of stone composition, calcium stones occurred in 118 cases $(63.8 \%)$ and 114 cases $(61.7 \%)$, struvite stones in 24 cases $(13.0 \%)$ and 32 cases (17.3\%), uric acid stones in 40 cases $(21.6 \%)$ and 36 cases $(19.5 \%)$, and cystine stones in 3 cases $(1.6 \%)$ and 3 cases (1.6\%) in groups A and B, respectively, with no significant difference between the two groups $(p=0.564)$. As for preoperative hydronephrosis, group A had significantly more hydronephrosis of at least a moderate degree $(\mathrm{p}=0.004$ and $\mathrm{p}=0.046)$. The operative time was longer in group $\mathrm{B}(113.6 \pm$ 48.3 minutes $)$ than in group $\mathrm{A}(87.3 \pm 32.7$ minutes, $\mathrm{p}$ $<0.001$ and $\mathrm{p}=0.012$ ). The underlying diseases included hypertension, diabetes mellitus, cardiovascular accident, chronic renal failure, and chronic liver disease for detailed comparison, without a significant difference between the two groups. Also, no statistically significant difference was found in the existing nephrostomy, history of previous abdominal operation, administration of anticoagulant medication, and thickness of the renal cortex between the two groups (Tables 2, 3).

\section{DISCUSSION}

PCNL is a noninvasive procedure in which directly viewed 
TABLE 3. Factors affecting total blood loss in the multivariate analysis

\begin{tabular}{lrcc}
\hline \multicolumn{1}{c}{ Factor } & p-value & $\begin{array}{c}\text { Odds } \\
\text { ratio }\end{array}$ & 95\% CI \\
\hline Body mass index & 0.032 & 1.100 & $1.009-1.200$ \\
Stone position & 0.001 & & \\
$\quad$ Staghorn (reference) & & 1 & \\
$\quad$ Renal pelvis & 0.029 & 0.354 & $0.138-0.801$ \\
$\quad$ Calyx & $<0.001$ & 0.100 & $0.033-0.307$ \\
$\quad$ Upper ureter & 0.015 & 0.242 & $0.077-0.755$ \\
Stone size & 0.048 & 1.005 & $1.001-1.009$ \\
Preoperative hydronephrosis & 0.046 & 0.711 & $0.509-0.994$ \\
Operation time & 0.012 & 1.012 & $1.003-1.021$ \\
\hline
\end{tabular}

CI, confidence interval.

stones are removed via a nephroscope through percutaneous nephrostomy. Since the first operation by Fernstrom and Johansson [2], PCNL has become generalized as a surgical treatment of renal stones with improved success rates owing to the development of new techniques and devices and the accumulation of experience [15-17]. White and Smith [18] described advantages of the procedure via a comparison of the results of PCNL and laparotomy, including reduced length of stay, smaller incision on the skin, less postoperative pain, quicker return to daily life, and relatively fewer complications.

However, the procedure is more invasive than extracorporeal shock wave lithotripsy or flexible ureteroscopic removal of stones, and several studies have reported that its incidence rate of complications is between $3 \%$ and $18 \%$ $[7,10,19]$. Such complications include renal bleeding, injury to the surrounding organs such as the intestine or the spleen, and pyelic perforation, among which renal bleeding is mostly common. Because PCNL is accompanied by bleeding during its surgical steps, including calyceal puncture, nephrostomy extension, and lithotripsy, transfusion is needed in some cases; the rate of transfusion is reported to be $3 \%$ to $23 \%$ [7-8,10,12,19-23]. In most cases, hemostasis can be achieved by conservative treatment including nephrostomy obstruction, fluid supply, or hemostatics, but in $0.3 \%$ to $1.4 \%$ of cases, an interventional procedure such as angioembolization is required [7-8,10,12,19-23].

Gradual dilatation of the nephrostomy is needed to minimize renal vessel injury, and balloon dilatation is reported to have a lower risk of bleeding and transfusion compared with dilatation using Amplatz or metal [24-26]. According to Safak et al. [26], transfusion was needed in $13.7 \%$ of cases of balloon dilatation and in $16.6 \%$ of cases of Amplatz dilatation. Balloon dilatation has a lower risk of bleeding because it does not require repetitive passing through the nephrostomy and its own pressure. In a case of intraoperative bleeding great enough to block the view, it is desirable to stop the procedure to wait for natural hemostasis. When bleeding is severe and natural hemostasis is not possible, renal angiography and artery embolism can reduce renal loss [27].

Venous bleeding in PCNL can be stopped only by allopathy owing to venous elasticity within the kidney, whereas artery injury that may induce severe bleeding requires angioembolization. The most common vascular lesion is arteriovenous fistula or pseudoaneurysm: arteriovenous fistula is formed by a higher difference in blood pressure between the injured artery and the injured adjacent vein and pseudoaneurysm formed by the bloodstream toward the renal parenchyme [23]. The rupture of the pseudoaneurysm may induce delayed bleeding [28]. Artery laceration is rare but may induce severe intraoperative bleeding. Although not observed in this study, there has been a report of a case of death by injury to the renal artery due to excessive nephrostomy dilatation [29]. Selective angioembolization after PCNL to stop severe bleeding shows a relatively higher success rate, a rate that is reported to be $92.3 \%[12,21,23]$.

In terms of studies of bleeding factors of PCNL, Stoller et al. [8] reported that the rate of transfusion was $23 \%$ in 96 patients out of 127 cases of PCNL. They described that renal bleeding was significantly reduced in cases of using the existing nephrostomy or of extending a single nephrostomy. Furthermore, no difference was found in degrees of renal bleeding and the postoperative bleeding rate was not significantly different according to the shape, position, composition, stone size, location of nephrostomy, and methods of nephrostomy dilatation. Gremmo et al. [30] retrospectively investigated 772 cases of PCNL to study the frequency of renal bleeding, treatment methods, and predictive factors for renal bleeding and reported that renal bleeding might not be able to be predicted because no significantly different factors between the bleeding group and the nonbleeding group were found. Kessaris et al. [12] reported that no factors affecting renal bleeding were found after investigating 2,200 patients undergoing PCNL on the basis of the patients' age, sex, concurrent diseases, stone size, number of nephrostomies, and operative time. By contrast, the results of our study indicate that bleeding may be significantly affected by the BMI of the patients, the size and position of the stones, and operative time, a difference of that may have been caused by differences in the method of nephrostomy dilatation, the devices used for lithotripsy, and the experience of the surgeons. For instance, Stoller et al. [8] included only four patients in whom balloon dilatation was applied, whereas a balloon was applied for nephrostomy dilatation in most of the patients in this study, which may have greatly affected bleeding.

Several researchers have reported that severe vessel injury by PCNL is directly associated with the complexity and size of stones. Kessaris et al. [12] reported that 8 patients out of 17 who needed angioembolization had staghorn stones, and Srivastava et al. [23] reported that the size of stones was an important factor for severe vessel injury. Turna et al. [9] reported that staghorn stones, diabetes, number of calyceal punctures, and stone size served as predictive factors of intraoperative bleeding in 193 patients who underwent PCNL, whereas El-Nahas et al. [29] re- 
ported that single stones, staghorn stones, and the experience of the surgeon had a significant correlation with intraoperative bleeding in 2,909 patients undergoing PCNL.

It is greatly important to clarify the risk factors for bleeding in order to reduce bleeding. Although this study is limited as a retrospective review, and as such random sampling was not conducted, it is significant in that the effects of the experience of the surgeon or surgical techniques were minimized because all procedures were conducted by a single surgeon. Also, the predictive factors for bleeding risk could be analyzed owing to sufficient samples for the patients. The results of the present study suggest that patient BMI, size and position of stones, and operative time may be factors predicting risk of bleeding in PCNL.

\section{CONCLUSIONS}

Our results, which were achieved by a single tract approach by a single experienced surgeon, show that staghorn calculi, BMI, severity of hydronephrosis, stone size, and operation time are associated with an increased risk of bleeding during PCNL. Endourologists should take into consideration whether patients have the aforementioned risk factors before performing PCNL. Prevention rather than treatment is more important; thus, we must always make efforts to reduce operation time when performing PCNL.

\section{CONFLICTS OF INTEREST}

The authors have nothing to disclose.

\section{ACKNOWLEDGMENTS}

This research was supported by Kyungpook National University Research Fund, 2012.

\section{REFERENCES}

1. Rupel E, Brown R. Nephroscopy with removal of stone following nephrostomy for obstructive calculous anuria. J Urol 1941;46: 177-82.

2. Fernstrom I, Johansson B. Percutaneous pyelolithotomy: a new extraction technique. Scand J Urol Nephrol 1976;10:257-9.

3. Alken P, Hutschenreiter G, Gunther R, Marberger M. Percutaneous stone manipulation. J Urol 1981;125:463-6.

4. Al-Kohlany KM, Shokeir AA, Mosbah A, Mohsen T, Shoma AM, Eraky I, et al. Treatment of complete staghorn stones: a prospective randomized comparison of open surgery versus percutaneous nephrolithotomy. J Urol 2005;173:469-73.

5. Preminger GM, Assimos DG, Lingeman JE, Nakada SY, Pearle MS, Wolf JS Jr, et al. Chapter 1: AUA guideline on management of staghorn calculi: diagnosis and treatment recommendations. J Urol 2005;173:1991-2000.

6. Labate G, Modi P, Timoney A, Cormio L, Zhang X, Louie M, et al. The percutaneous nephrolithotomy global study: classification of complications. J Endourol 2011;25:1275-80.

7. Lee WJ, Smith AD, Cubelli V, Badlani GH, Lewin B, Vernace F, et al. Complications of percutaneous nephrolithotomy. AJR Am J Roentgenol 1987;148:177-80.

8. Stoller ML, Wolf JS Jr, St Lezin MA. Estimated blood loss and transfusion rates associated with percutaneous nephrolitho- tomy. J Urol 1994;152(6 Pt 1):1977-81.

9. Turna B, Nazli O, Demiryoguran S, Mammadov R, Cal C. Percutaneous nephrolithotomy: variables that influence hemorrhage. Urology 2007;69:603-7.

10. Segura JW, Patterson DE, LeRoy AJ, Williams HJ Jr, Barrett DM, Benson RC Jr, et al. Percutaneous removal of kidney stones: review of 1,000 cases. J Urol 1985;134:1077-81.

11. Liatsikos EN, Kallidonis P, Stolzenburg JU, Ost M, Keeley F, Traxer O, et al. Percutaneous management of staghorn calculi in horseshoe kidneys: a multi-institutional experience. J Endourol 2010;24:531-6.

12. Kessaris DN, Bellman GC, Pardalidis NP, Smith AG. Management of hemorrhage after percutaneous renal surgery. J Urol 1995;153(3 Pt 1):604-8.

13. Akman T, Binbay M, Sari E, Yuruk E, Tepeler A, Akcay M, et al. Factors affecting bleeding during percutaneous nephrolithotomy: single surgeon experience. J Endourol 2011;25:327-33.

14. McCullough TC, Roth JV, Ginsberg PC, Harkaway RC. Estimated blood loss underestimates calculated blood loss during radical retropubic prostatectomy. Urol Int 2004;72:13-6.

15. Whitfield HN, Mills VA. Percutaneous nephrolithotomy: a report of 150 cases. Br J Urol 1985;57:603-4.

16. Wong MY. An update on percutaneous nephrolithotomy in the management of urinary calculi. Curr Opin Urol 2001;11:367-72.

17. Lingeman JE, Coury TA, Newman DM, Kahnoski RJ, Mertz JH, Mosbaugh PG, et al. Comparison of results and morbidity of percutaneous nephrostolithotomy and extracorporeal shock wave lithotripsy. J Urol 1987;138:485-90.

18. White EC, Smith AD. Percutaneous stone extraction from 200 patients. J Urol 1984;132:437-8.

19. el-Kenawy MR, el-Kappany HA, el-Diasty TA, Ghoneim MA. Percutaneous nephrolithotripsy for renal stones in over 1000 patients. Br J Urol 1992;69:470-5.

20. Sacha K, Szewczyk W, Bar K. Massive haemorrhage presenting as a complication after percutaneous nephrolithotomy (PCNL). Int Urol Nephrol 1996;28:315-8.

21. Patterson DE, Segura JW, LeRoy AJ, Benson RC Jr, May G. The etiology and treatment of delayed bleeding following percutaneous lithotripsy. J Urol 1985;133:447-51.

22. Martin X, Murat FJ, Feitosa LC, Rouviere O, Lyonnet D, Gelet A, et al. Severe bleeding after nephrolithotomy: results of hyperselective embolization. Eur Urol 2000;37:136-9.

23. Srivastava A, Singh KJ, Suri A, Dubey D, Kumar A, Kapoor R, et al. Vascular complications after percutaneous nephrolithotomy: are there any predictive factors? Urology 2005;66:38-40.

24. Davidoff R, Bellman GC. Influence of technique of percutaneous tract creation on incidence of renal hemorrhage. J Urol 1997;157: 1229-31.

25. Heggagi MA, Karsza A, Szule E Jr. Use of different types of dilator systems in the prevention of complications of percutaneous (PC) renal surgery. Acta Chir Hung 1991;32:365-9.

26. Safak M, Gogus C, Soygur T. Nephrostomy tract dilation using a balloon dilator in percutaneous renal surgery: experience with 95 cases and comparison with the fascial dilator system. Urol Int 2003;71:382-4.

27. Tefekli A, Ali Karadag M, Tepeler K, Sari E, Berberoglu Y, Baykal $\mathrm{M}$, et al. Classification of percutaneous nephrolithotomy complications using the modified clavien grading system: looking for a standard. Eur Urol 2008;53:184-90.

28. Gavant ML, Gold RE, Church JC. Delayed rupture of renal pseudoaneurysm: complication of percutaneous nephrostomy. AJR Am J Roentgenol 1982;138:948-9. 
29. El-Nahas AR, Shokeir AA, El-Assmy AM, Mohsen T, Shoma AM, Eraky I, et al. Post-percutaneous nephrolithotomy extensive hemorrhage: a study of risk factors. J Urol 2007;177:576-9.
30. Gremmo E, Ballanger P, Dore B, Aubert J. Hemorrhagic complications during percutaneous nephrolithotomy. Retrospective studies of 772 cases. Prog Urol 1999;9:460-3. 